\title{
Gambaran Kadar Natrium dan Kalium Plasma Berdasarkan Status Nutrisi Sebelum dan Sesudah Rehidrasi pada Kasus Diare yang Dirawat Di Departemen IKA RSCM
}

\author{
Hasri Salwan*, Agus Firmansyah**, Aswitha Boediarso**, Badriul Hegar**, Muzal \\ Kadim**, Fatima Safira Alatas** \\ *Bagian Ilmu Kesehatan Anak Fakultas Kedokteran Universitas Sriwijaya Palembang \\ **Bagian Ilmu Kesehatan Anak Fakultas Kedokteran Universitas Indonesia, RS Dr Cipto \\ Mangunkusumo, Jakarta
}

Latar belakang. Pemberian cairan rehidrasi parenteral dapat mengatasi gangguan natrium (Na) dan kalium (K) plasma pada anak dengan diare. Status nutrisi dapat mempengaruhi perbaikan gangguan $\mathrm{Na}$ dan $\mathrm{K}$ plasma saat rehidrasi. Respon perbaikan kadar $\mathrm{Na}$ dan $\mathrm{K}$ plasma pada anak diare dengan status nutrisi kurang dan buruk (NKB) berbeda dengan anak status nutrisi baik (NB)

Tujuan Menilai pengaruh status nutrisi terhadap kadar Na, K plasma, dan perubahannya pada saat dehidrasi dan rehidrasi.

Metode. Penelitian potong lintang retrospektif terhadap data sekunder pasien diare yang dirawat di Departemen IKA RSCM dengan rehidrasi mengunakan cairan KAEN 3B. Kelompok penelitian dibagi menjadi kelompok nutrisi baik (NB) dan kelompok nutrisi kurang dan buruk (NKB). Jumlah subjek penelitian 32 pada setiap kelompok. Faktor perancu yaitu muntah, demam, terapi oralit, dan gambaran klinis diare.

Hasil. Status nutrisi BB/TB kelompok NB 105,1 $\pm 10,7$ dan kelompok NKB 78,2 $\pm 12,0$, dengan nutrisi buruknya 28,1\%. Pada kelompok NB, kadar Na dehidrasi 135,4 $\pm 8,17$ meq/l, rehidrasi 138,6 $\pm 6,73$ meq/l, meningkat $3,2 \pm 8,70 \mathrm{meq} / \mathrm{l}$. Pada kelompok NKB, kadar Na dehidrasi 134,3 $\pm 7,12 \mathrm{meq} / \mathrm{l}$, rehidrasi 132,2 $\pm 5,23 \mathrm{meq} / \mathrm{l}$,

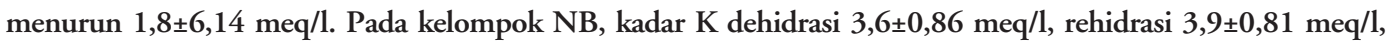

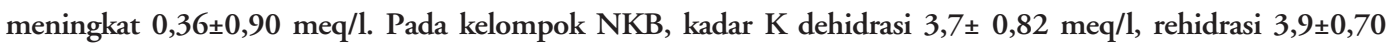
meq/l, meningkat 0,26 $\pm 0,70 \mathrm{meq} / \mathrm{l}$. Kesemuanya tidak berbeda bermakna ( $>0,05)$ antara gizi baik atau kurang/ buruk. Dari semua variabel perancu muntah $(\mathrm{p}=0,009)$ dan komplikasi $(\mathrm{p}=0,026)$ yang tersebar tidak merata. Kesimpulan. Tidak didapatkan perbedaan kadar Na dan $\mathrm{K}$ saat dehidrasi, rehidrasi, dan perubahannya pada kelompok NB dan NKB (Sari Pediatri 2008;9(6):406-11).

Kata kunci: $\mathrm{Na}, \mathrm{K}$, diare, nutrisi kurang dan buruk, anak.

\footnotetext{
Alamat korespondensi

Dr. Hasri Salwan, Sp.A., Staf fungsional Departemen IKA Universitas Sriwijaya/ RS Muh. Husin. Jl Jend Sudirman KM 3,5 Palembang

Sumatera Selatan 30126. Telp. 0711372832
} 
$\mathrm{P}$ enyakit diare dan nutrisi buruk merupakan salah satu penyebab utama kesakitan dan kematian pada anak di negara-negara berkembang. Pengelolaan diare yang dianjurkan WHO telah berhasil mengurangi lebih dari 95\% kematian oleh diare. Pemberian cairan merupakan langkah pertama dan terpenting dalam pengelolahan diare. Pemberian cairan dapat dilakukan secara oral atau parenteral. ${ }^{1}$

Natrium dan Kalium merupakan elektrolit yang penting bagi tubuh. Kadar Na dan K dapat mengalami perubahan oleh beberapa keadaan, seperti gangguan diet, diare, nutrisi buruk, asidosis, alkalosis, gangguan fungsi ginjal, dan lain-lain. ${ }^{2}$ Diare menyebabkan hilangnya air dan elektrolit terutama $\mathrm{Na}$ dan $\mathrm{K}$ dalam jumlah besar sehingga mengakibatkan dehidrasi, gangguan keseimbangan elektrolit, dan gangguan keseimbangan asam basa. ${ }^{1}$

Natrium merupakan komponen utama elektrolit cairan ektraselular (CES), berperan menjaga osmolaritas CES, yang berarti diperlukan untuk mempertahankan volume CES. Kadar Na mengalami perubahan pada diare dan gangguan nutrisi. ${ }^{1}$ Pasien diare akut kehilangan $\mathrm{Na}$ dalam feses sekitar 50-98 $\mathrm{mEq} / \mathrm{l}$, sedangkan pada fase penyembuhan 34-46 $\mathrm{mEq} / \mathrm{l}^{3}$ Pada nutrisi buruk, kadar Na serum rendah, tetapi kandungan total $\mathrm{Na}$ tubuh relatif tinggi karena banyak $\mathrm{Na}$ masuk ke ruang intraseluler., ${ }^{2,4}$

Kalium merupakan komponen utama elektrolit cairan intraselular (CIS). Kadar K dalam CIS yang tinggi merupakan pool $\mathrm{K}$ dalam tubuh. Walaupun kadar K dalam CES rendah, tetapi kadarnya dapat mencerminkan pool $\mathrm{K}$ tubuh. ${ }^{1}$ Pasien diare akut kehilangan K dalam feses sekitar 29-46 mEq/l, sedangkan pada fase penyembuhan meningkat menjadi 37-65 mEq/l. ${ }^{3}$ Penurunan K total selain terjadi pada diare, juga terjadi pada status nutrisi buruk. ${ }^{2,4}$

WHO (World health organization) menganjurkan pemakaian RL (ringer laktat) dalam mengatasi dehidrasi berat dan dehidrasi ringan sedang di saat pemberian cairan peroral tidak memungkinkan, disertai oralit dan makanan yang kaya $\mathrm{K}$ setelah keadaan umum anak membaik. ${ }^{1}$ Di RSCM/FKUI cairan yang dipakai adalah KAEN 3B, perbedaan cairan KAEN 3B dan RL adalah kadar Na pada RL (130 meq/l) lebih tinggi dibandingkan KAEN 3B (50 meq/l), sedangkan kadar K pada RL ( 4 meq/l) lebih rendah dibandingkan KAEN 3B (20 meq/l). Perbedaan lain RL tidak mengandung sumber energi, berlainan dengan KAEN 3B yang mengandung dektrosa 2,7\%. ${ }^{5}$ Pemberian cairan rehidrasi parenteral dapat mengatasi gangguan $\mathrm{Na}$ dan $\mathrm{K}$ plasma pada anak dengan diare. Respon perbaikan kadar $\mathrm{Na}$ dan $\mathrm{K}$ plasma pada anak diare dengan status NKB berbeda dengan anak status NB. ${ }^{2}$ Perlu dilakukan penelitian untuk menilai pengaruh status nutrisi terhadap kadar $\mathrm{Na}$ dan $\mathrm{K}$ plasma serta perubahannya pada anak diare

\section{Metode}

Penelitian potong lintang retrospektif, data sekunder diperoleh dari catatan medik pasien diare yang dirawat di Departemen IKA RSCM/FKUI. Kriteria inklusi, meliputi seluruh kasus diare dengan derajat dehidrasi ringan-sedang atau dehidrasi berat tanpa memandang etiologi, mendapat cairan rehidrasi KAEN 3B, berumur 1 bulan atau lebih. Subjek tidak diikutsertakan jika dijumpai penyakit ginjal, diabetes militus, atau diabetes insipidus. Jumlah subjek minimal yang diperlukan 32 pada masing-masing kelompok. Subjek dibagi menjadi 2 kelompok berdasarkan status nutrisi, (kelompok NB dan kelompok NKB) dan dinilai kadar $\mathrm{Na}$, K plasma saat dehidrasi, saat rehidrasi, dan perubahannya. Beberapa faktor yang diperkirakan sebagai perancu dijabarkan pada kedua kelompok dan dinilai perbedaan penyebarannya.

\section{Hasil}

Selama Juli 2003 sampai Desember 2007 didapatkan 64 pasien diare. Jenis kelamin dan umur tersebar merata di kedua kelompok penelitian. Rerata status nutrisi BB/TB pada kelompok NB 105,1 $\pm 10,7$ berbeda bermakna $(\mathrm{p}=0,000)$ dibandingkan kelompok NKB 78,2 $\pm 12,0$. Distribusi karakteristik umum subjek penelitian tertera pada Tabel 1 .

Beberapa faktor perancu dapat berasal dari gambaran klinis, pemakaian oralit di rumah, dan penyakit diare. Pada Tabel 2 dan 3 tertera penyebaran faktor perancu pada kedua kelompok penelitian.

Pada Tabel 4 tertera kadar Na dan K plasma saat dehidrasi, rehidrasi dan perubahannya pada kedua kelompok penelitian. Tabel 5 memperlihatkan distribusi jumlah status kadar elektrolit pada kedua kelompok penelitian. 
Tabel 1. Distribusi karateristik umum subjek penelitian pada kelompok NB dan kelompok NKB

\begin{tabular}{|c|c|c|c|}
\hline \multirow{2}{*}{ Karakteristik } & \multicolumn{2}{|c|}{ Kelompok Subjek } & \multirow{2}{*}{$p$} \\
\hline & $\mathrm{NB}(\mathrm{N}=32)$ & NKB $(\mathrm{N}=32)$ & \\
\hline Jenis kelamin ${ }^{\Uparrow} / q$ & $16 / 16$ & $15 / 17$ & $1,000^{*}$ \\
\hline Umur, rerata (bulan): & $15,0 \pm 29,39$ & $12,1 \pm 14,79$ & $0,620^{* *}$ \\
\hline $1-11$ bulan $/ \geq 12$ bulan & $11 / 21$ & $12 / 20$ & $1,000^{*}$ \\
\hline Status Nutrisi (BB/TB): rerata & $105,1 \pm 10,7$ & $78,2 \pm 12,0$ & $0,000^{* *}$ \\
\hline Normal 90-110\% & $24(75,0 \%)$ & & $0,000^{*}$ \\
\hline Di atas normal 111-130\% & $8(25,0 \%)$ & & \\
\hline Nutrisi kurang $70-<90 \%$ & & $23(71,9 \%)$ & \\
\hline Nutrisi buruk < $70 \%$ & & $9(28,1 \%)$ & \\
\hline
\end{tabular}

Ket: ${ }^{*}: \mathrm{x}^{2}$ test, ${ }^{* *} \mathrm{t}$-test

Tabel 2. Distribusi subjek berdasarkan gambaran klinis dan pemakaian oralit pada kelompok NB dan kelompok NKB

\begin{tabular}{|c|c|c|c|c|c|c|c|}
\hline \multirow{2}{*}{$\begin{array}{l}\text { Gambaran klinis dan } \\
\text { Pemakaian oralit }\end{array}$} & \multicolumn{3}{|c|}{ Kelompok NB $(\mathrm{n}=32)$} & \multicolumn{3}{|c|}{ Kelompok NKB $(\mathrm{n}=32)$} & \multirow{2}{*}{$p^{*}$} \\
\hline & Ya & Tidak & Data $(-)$ & Ya & Tidak & Data $(-)$ & \\
\hline Muntah & 24 & 8 & 0 & 12 & 19 & 1 & 0,009 \\
\hline Riwayat demam/ panas & 31 & 1 & 0 & 25 & 7 & 0 & 0,053 \\
\hline Pemakaian oralit & 15 & 16 & 1 & 17 & 14 & 1 & 0,879 \\
\hline
\end{tabular}

Keterangan: *: $\mathrm{x}^{2}$ test

Tabel 3. Gambaran penyakit diare pada kelompok NB dan kelompok NKB

\begin{tabular}{lccc}
\hline \multirow{2}{*}{ Gambaran penyakit diare } & \multicolumn{2}{c}{ Kelompok Subjek } & \multirow{2}{*}{$p$} \\
\cline { 2 - 3 } & $\mathrm{NB}(\mathrm{N}=32)$ & $\mathrm{NKB}(\mathrm{N}=32)$ & \\
\hline Lama diare di rumah (hari) & $6,5 \pm 6,78$ & $9.0 \pm 17,00$ & $0,472^{* *}$ \\
Frekuensi b.a.b maks di rumah (kali/hari) & $7,9 \pm 3,98$ & $8,2 \pm 3,20$ & $0,810^{* *}$ \\
Lama diare di rumah (hari) & $6,5 \pm 6,78$ & $9.0 \pm 17,00$ & $0,472^{* *}$ \\
Jenis diare: akut/memanjang/persisten (kronis) & $14 / 9 / 9$ & $8 / 15 / 9$ & $0,208^{*}$ \\
Derajat dehidrasi: ringan-sedang/berat & $13 / 19$ & $12 / 20$ & $1,000^{*}$ \\
Jenis terapi rehidrasi: cepat/lambat & $22 / 10$ & $17 / 15$ & $0,305^{*}$ \\
Komplikasi: asidosis/ensefalopati/syok & $17 / 4 / 8$ & $9 / 1 / 7$ & $0,026^{*}$ \\
\hline
\end{tabular}

Keterangan: ${ }^{*} \mathrm{x}^{2}$ test ${ }^{* *}$ t-test, b.a.b=buang air besar

Tabel 4. Kadar Na dan K plasma saat dehidrasi, rehidrasi, dan perubahannya pada kelompok NB dan kelompok NKB

\begin{tabular}{lccccc}
\hline \multirow{2}{*}{ Kadar elektrolit } & \multicolumn{5}{c}{ Kelompok Subjek } \\
\cline { 2 - 5 } & \multicolumn{2}{c}{ Kelompok NB } & \multicolumn{2}{c}{ Kelompok NKB } & \multirow{2}{*}{ p $^{*}$} \\
\cline { 2 - 4 } & Kadar & Rentang & Kadar & Rentang & \\
\hline Na dehidrasi (meq/l) & $135,4 \pm 8,17$ & $120-148$ & $134,3 \pm 7,12$ & $122-157$ & 0,592 \\
Na rehidrasi (meq/l) & $138,6 \pm 6,73$ & $126-157$ & $132,2 \pm 5,23$ & $125-145$ & 0,117 \\
Perubahan Na (meq/l) & $3,2 \pm 8,70$ & $-13-18$ & $1,8 \pm 6,14$ & $-12-15$ & 0,468 \\
K dehidrasi (meq/l) & $3,6 \pm 0,86$ & $1,7-4,9$ & $3,7 \pm 0,82$ & $2,0-5,0$ & 0,624 \\
K rehidrasi (meq/l) & $3,9 \pm 0,81$ & $2,4-5,8$ & $3,9 \pm 0,70$ & $1,8-5,2$ & 0,987 \\
Perubahan K (meq/l) & $0,36 \pm 0,90$ & $-1,5-2,2$ & $0,26 \pm 0,70$ & $-1,2-1,8$ & 0,579 \\
\hline
\end{tabular}

Keterangan: ${ }^{*}$ t -test 
Hasri Salwan dkk: Kadar Natrium dan Kalium Plasma Berdasarkan Status Nutrisi Sebelum dan Sesudah Rehidrasi pada Kasus Diare

Tabel 5. Distribusi kadar Na dan K saat dehidrasi, rehidrasi, dan perubahannya pada kelompok NB dan NKB

\begin{tabular}{lcccccc}
\hline \multirow{2}{*}{$\begin{array}{c}\text { Distribusi Kadar Na dan K } \\
\text { (meq/l) }\end{array}$} & \multicolumn{6}{c}{ Kelompok Subjek } \\
\cline { 2 - 7 } & Dehidrasi & Rehidrasi & Perubahan & Dehidrasi & Rehidrasi & Perubahan \\
\cline { 2 - 7 } & 13 & 6 & -7 & 17 & 10 & -7 \\
\hline Hiponatremia $(<135)$ & 19 & 25 & 6 & 14 & 22 & 8 \\
Normonatremia $(135-150)$ & 0 & 1 & 1 & 1 & 0 & -1 \\
Hipernatremia $(>150)$ & 14 & 9 & -5 & 14 & 8 & -6 \\
Hipokalemia $(<3,5)$ & 18 & 22 & 4 & 18 & 24 & 6 \\
Normokalemia $(3,5-5,5)$ & 0 & 1 & 1 & 0 & 0 & 0 \\
Hiperkalemia $(>5,5)$ & & &
\end{tabular}

\section{Diskusi}

Beberapa faktor perancu yang dapat mempengaruhi kadar $\mathrm{Na}$ dan $\mathrm{K}$ diuraikan pada kedua kelompok penelitian, yakni muntah, demam, pemakaian oralit, dan gambaran penyakit diare. Sebagian besar variabel tersebar merata di kedua kelompok penelitian, kecuali muntah $(\mathrm{p}=0,009)$ dan komplikasi $(\mathrm{p}=0,026)$. Pada kelompok NB, muntah lebih banyak terjadi $(\mathrm{p}=0,009)$ dibandingkan kelompok NKB, namun peneliti tidak menelusuri lebih lanjut apa penyebabnya. Gejala muntah dapat dihubungkan dengan penyebab muntah yang lain seperti demam, diare akut, asidosis, dan ensefalopati yang terjadi pada kelompok NB. Pada kelompok NB, komplikasi lebih banyak terjadi $(\mathrm{p}=0,009)$.

Pada kelompok NB, kadar $\mathrm{Na}$ saat dehidrasi $135,4 \pm 8,17 \mathrm{meq} / \mathrm{l}$ dan saat rehidrasi $138,6 \pm 6,73 \mathrm{meq} /$ 1 , meningkat 3,2 $\pm 8,70 \mathrm{meq} / \mathrm{l}$. Pada kelompok NKB kadar $\mathrm{Na}$ saat dehidrasi $134,3 \pm 7,12 \mathrm{meq} / \mathrm{l}$ dan saat rehidrasi $132,2 \pm 5,23 \mathrm{meq} / \mathrm{l}$, menurun $1,8 \pm 6,14 \mathrm{meq} / \mathrm{l}$. $\mathrm{Hadi}^{7}$ yang mempergunakan RL selama 4 jam mendapatkan penurunan kadar Na pada kelompok NB dari $134,6 \pm 7,13 \mathrm{meq} / \mathrm{l}$ saat dehidrasi menjadi $133,5 \pm 8,71 \mathrm{meq} / \mathrm{l}$ saat rehidrasi $(\mathrm{p}=0,453)$ dan pada kelompok NKB penurunan lebih besar dari 129,2 $\pm 6,01$ $\mathrm{meq} / \mathrm{l}$ saat dehidrasi menjadi $127,4 \pm 7,42 \mathrm{meq} / \mathrm{l}$ saat rehidrasi $(\mathrm{p}=0,097)$. Pada penelitian Hadi, ${ }^{7}$ kadar $\mathrm{Na}$ dinilai saat rehidrasi 4 jam, sementara sistem keseimbangan air dan elektrolit dipertahankan melalui integrasi dan fungsi ginjal, hormonal, dan saraf yang memerlukan waktu 4-6 jam untuk bekerja. Mekanisme keseimbangan untuk menjaga volume dan osmolaritas CES. Dapat dilihat pada penelitian Jonardi ${ }^{8}$ dan Hernawan $\mathrm{dkk},{ }^{9}$ Jonardi ${ }^{8}$ memberikan RL selama 3 jam mendapatkan rerata kadar Na saat dehidrasi 134,6 meq/
1 (rentang 121-155 meq/l), menurun saat rehidrasi 136 meq/l (128-149 meq/l), dan setelah 24 jam meningkat menjadi 140,4 meq/l (133-149 meq/l). Hernawan $\mathrm{dkk}^{9}$ yang memberikan RL selama 7 jam mendapatkan hasil saat dehidrasi kadar Na rerata $133 \mathrm{meq} / 1$ (117-160 meq/ 1) dan meningkat saat rehidrasi menjadi $136 \mathrm{meq} / \mathrm{l}$ (130$148 \mathrm{meq} / \mathrm{l})$. Tidak ada hubungan antara status nutrisi $(\mathrm{p}=0,468)$ pada perubahan kadar $\mathrm{Na}$ saat dehidrasi dan rehidrasi, walaupun pada kelompok NB terjadi peningkatan, dan kelompok NKB terjadi penurunan. Hasil yang sama didapatkan Caksen $\mathrm{dkk}^{10}$ bahwa tidak ada perbedaan antara kadar $\mathrm{Na}$ plasma dengan derajat malnutrisi dan lama diare (akut atau kronis). Cairan KAEN 3B mengandung $\mathrm{Na}$ yang dapat meningkatkan kadar Na saat rehidrasi pada kelompok NB, tetapi tidak pada kelompok NKB. Pada kelompok NKB, rehidrasi dengan cairan berkadar $\mathrm{Na}$ rendah perlu dilakukan karena pada NKB terutama yang berat terjadi penurunan relatif kadar $\mathrm{Na}$ CES, sementara kadar $\mathrm{Na}$ CIS lebih besar. ${ }^{4}$

Pada kelompok NB, kadar K saat dehidrasi $3,6 \pm 0,86 \mathrm{meq} / \mathrm{l}$ dan saat rehidrasi $3,9 \pm 0,81 \mathrm{meq} / \mathrm{l}$, meningkat $0,36 \pm 0,90 \mathrm{meq} / \mathrm{l}$. Pada kelompok NKB kadar $K$ saat dehidrasi $3,7 \pm 0,82 \mathrm{meq} / \mathrm{l}$ dan saat rehidrasi $3,9 \pm 0,70 \mathrm{meq} / \mathrm{l}$, meningkat $0,26 \pm 0,70 \mathrm{meq} /$ 1. Tidak ada perbedaan $(\mathrm{p}>0,05)$ pada kedua kelompok penelitian dalam hal kadar $\mathrm{K}$ dan perubahannya pada saat dehidrasi dan saat rehidrasi. Kadar K pada kedua kelompok penelitian meningkat pada saat rehidrasi dibandingkan saat dehidrasi. Temuan ini bertentangan dengan hasil penelitian Hadi $^{11}$ dan Jonardi ${ }^{8}$ yang mengunakan RL. Hadi ${ }^{11}$ mendapatkan penurunan kadar K pada kelompok NB dari $3,9 \pm 0,63 \mathrm{meq} / \mathrm{l}$ saat dehidrasi menjadi $3,3 \pm 0,52$ $\mathrm{meq} / \mathrm{l}$ saat rehidrasi $4 \mathrm{jam}(\mathrm{p}=0,000)$ dan pada kelompok NKB dari 3,6 $\pm 0,69 \mathrm{meq} / \mathrm{l}$ saat dehidrasi 
menjadi $2,7 \pm 0,52 \mathrm{meq} / 1$ saat rehidrasi 4 jam $(\mathrm{p}=0,000)$. Jonardi ${ }^{8}$ mendapatkan rerata kadar $\mathrm{K}$ saat dehidrasi 3,74 meq/l (2,4-5,7 meq/l), saat rehidrasi 3 jam 3,41 meq/l $(1,8-5,4 \mathrm{meq} / \mathrm{l})$, dan setelah 24 jam 3,62 meq/l (2,4-4,8 meq/l). Kadar K pada RL rendah (4 meq/l) dibandingkan KAEN 3B $(20$ meq/ 1). Oleh karena itu WHO/Depkes ${ }^{1}$ menganjurkan setelah keadaan memungkinkan segera memberikan asupan oralit dan makanan yang mengandung K yang tinggi. Disamping itu, integrasi dan fungsi-fungsi ginjal, hormonal, saraf memerlukan waktu dalam mempertahankan volume dan osmolaritas CES, seperti yang diperlihatkan pada penelitian Jonardi setelah 24 jam rehidrasi kadar K meningkat. Hernawan $\mathrm{dkk}^{9}$ mendapatkan pemberian RL dapat meningkatkan kadar $\mathrm{K}$ dari rerata $3,1 \mathrm{meq} / \mathrm{l}$ saat dehidrasi (1,7-6,8 meq/l) menjadi 4,7 meq/l (2,1$6,5 \mathrm{meq} / \mathrm{l})$ saat rehidrasi setelah 7 jam.

Perbaikan hiponatremia saat rehidrasi pada kelompok NB dan NKB terjadi pada masing-masing 7 pasien (21,9\%). Hipernatremia saat rehidrasi pada kelompok NB terjadi pada 1 pasien $(3,1 \%)$ sedangkan pada kelompok NKB tidak ditemukan. Jadi, walaupun KAEN 3B mengandung $\mathrm{Na}$ rendah, masih dapat meningkatkan kadar $\mathrm{Na}$ (Tabel 4) pada pasien (Tabel 5) kelompok $\mathrm{NB}$ dan mempertahankan kadar $\mathrm{Na}$ (Tabel 4) dan meningkatkan jumlah pasien normonatremia (Tabel 5) pada kelompok NKB. Pada penelitian Jonardi ${ }^{8}$ hiponatremia $(130 \mathrm{meq} / \mathrm{l})$ saat dehidrasi terjadi pada 4 pasien $(19,1 \%)$, saat rehidrasi 3 jam pada 1 pasien $(4,7 \%)$, dan setelah 24 jam tidak ditemukan $(0 \%)$.

Perbaikan hipokalemia saat rehidrasi pada kelompok NB terjadi pada 5 pasien $(15,6 \%)$ dan pada kelompok NKB pada 6 pasien (18,8\%). Hiperkalemia saat rehidrasi pada kelompok NB terjadi pada 1 pasien $(3,1 \%)$ dan tidak ditemukan pada kelompok NKB. Walaupun KAEN 3B mengandung $\mathrm{K}$ yang tinggi tetapi kejadian hipokalemia saat rehidrasi tetap lebih sering terjadi dan hanya 1 pasien yang mengalami hiperkalemia $(5,8 \mathrm{mEq} / \mathrm{l})$. Hal tersebut dapat difahami, karena untuk mengkoreksi keadaan hipokalemia perlu waktu 3 sampai 5 hari. Pada penelitian Ahmed dkk, ${ }^{12}$ pemberian oralit yang mengandung kalium 20 meq/l, K plasma turun secara signifikan $(\mathrm{p}<0,01)$ pada 24 jam setelah dirawat dan masih tetap turun setelah 48 jam, walaupun pemberian oralit tetap diberikan. Jonardi ${ }^{8}$ mendapatkan hipokalemia $(2,5$ meq/l) pada saat dehidrasi terjadi pada 2 pasien $(9,5 \%)$, saat rehidrasi 3 jam pada 4 pasien (19,1\%), dan 2 pasien setelah 24 jam (9,5\%).

Masih banyak perdebatan mengenai jenis cairan rehidrasi intravena pada pasien diare. Menurut Neville $\mathrm{dkk},{ }^{13}$ pengobatan dehidrasi dengan larutan salin normal $(\mathrm{NaCl} 0,9 \%+2,5 \%$ dektrose) pada kasus gastroenteritis lebih baik dibandingkan larutan salin hipotonik ( $\mathrm{NaCl} 0,45 \%+2,5 \%$ dektrose) karena dapat mengatasi hiponatremia tanpa kejadian hipernatremia. Eisenhut ${ }^{14}$ mengemukakan pemberian salin isotonik dapat menyebabkan hiperkloremik asidosis. Penelitian meta-analisis Choong $\mathrm{dkk}^{15}$ mendapatkan larutan hipotonik meningkatkan risiko terjadi hiponatremia akut dan menyebabkan morbiditas yang lebih tinggi. Tidak ada larutan yang ideal (baik kecepatan dan komposisi) untuk semua anak, tetapi larutan yang isotonik atau mendekati isotonik lebih fisiologis dan menjadi pilihan yang lebih aman pada fase akut penyakit atau pada periode perioperatif. Hiponatremia terjadi akibat keseimbangan positif dari pemberian cairan bebas $\mathrm{Na}$ dan ketidakmampuan mensekresi urin yang hipotonik akibat sekresi ADH. Hormon ADH dikeluarkan jika terjadi keadaan hipovolumia dan hipoosmolar, jika kedua keadaan tersebut terjadi bersamaan, maka $\mathrm{ADH}$ lebih merespon hipovolemia dengan akibat hipoosmolar semakin berat. ${ }^{15}$

Kekurangan penelitian retrospektif adalah kelompok $\mathrm{NKB}$ memiliki rerata status nutrisi $\mathrm{BB} / \mathrm{TB}$ $78,2 \pm 12,0$ (tidak mewakili gangguan nutrisi yang berat), tidak dilakukan pengukuran kadar $\mathrm{Na}$ dan $\mathrm{K}$ urin dan feses, dan outcome lainnya selain kadar $\mathrm{Na}$ dan $\mathrm{K}$ pasca rehidrasi tidak diteliti. Efektifitas suatu cairan dalam rehidrasi tidak hanya ditujukan pada stabilitas kadar $\mathrm{Na}$ dan $\mathrm{K}$, tetapi juga pada outcome yang lain, misalnya kecepatan mengatasi asidosis dan gagal ginjal akut hilang.

\section{Kesimpulan dan Saran}

Disimpulkan bahwa tidak ditemukan perbedaan kadar $\mathrm{Na}$ dan $\mathrm{K}$ saat dehidrasi dan saat rehidrasi serta perubahannya pada kelompok NB dan NKB. Penelitian lanjutan perlu dilakukan dengan metode prospektif, agar subjek mendapat perlakuan yang sama, memiliki perbedaan status nutrisi yang ekstrim, mempertimbangkan kadar $\mathrm{Na}$ dan $\mathrm{K}$ urin dan feses, dan melihat outcome lainnya, mempergunakan desain penelitian yang baik. 


\section{Daftar Pustaka}

1. Sunoto, Soeparto PSW, Soenarto Y, Ismail R. Buku ajar diare. Jakarta: Dep Kes RI Ditjen PPM \& PLP; 1990.

2. Hansen JD, Pettifor JM. Prfotein energy malnutrition. Dalam: McLaren DS, Burman D, Belton NR, Williams AF. Textbook of paediatric nutrition. Edinburgh: Churchill Livingstone; 1991. h. 357-90.

3. Santosham M, Greenough WB. Treatment of dehydration and oral rehydration therapy. Dalam: Gracey M. Diarrhea. Boston: CRC Press; 1991. h. 185-209.

4. Ashworth A, Khanum S, Jackson A, Schofield C. Guidelines for the inpatients treatment of severely malnourished children. WHO; 2003.

5. Anonim. Pedoman cairan infuse. Edisi revisi IX. Jakarta: PT Otsuka Indonesia; 2007.

6. Khine ZT, Maung KU, Khin M, Myint YY, Thi M, May KK. Sodium balance during acute diarrhea in malnourished children. J Tropic Pediatr 1993;38:153-7.

7. Hadi SF. Spektrum kadar natrium darah sebelum dan sesudah direhidrasi menggunakan ringer laktat pada penderita gastroenteritis akut dehidrasi berat dan hubungannya dengan status nutrisi. Tesis. Palembang: Bagian IKA FK UNSRI; 2000.
8. Jonardi. Pengobatan rehidrasi parenteral cepat pada diare akut dehidrasi berat. Studi observasional analitik. Tesis. Jakarta: Bagian IKA FKUI; 1990.

9. Hermawan, Sunoto, Pusponegoro TS. Treatment of acute infantile gastroenteritis dehydration acidosis with Ringer's lactate and glucose-electrolyte solution. Pediatr Indones 1978; 18:83-9

10. Caksen H, Odaba D, Sar S. Hyponatremic dehydration: an analysis of 78 cases. Intr Urol Nephr 2001;33:445-8.

11. Hadi. Kadar kalium darah pada penderita diare akut dehidrasi berat yang direhidrasi dengan cairan ringer laktat. Tesis. Palembang: Bagian IKA FK UNSRI; 1999.

12. Ahmed ASM, Islam MR, Kabir I. Efficacy of oral rehidration in correcting serum potassium deficit of children with acute diarrhea in Bangladesh. JTrop Pediatr 1988; 34:24-27.

13. Neville KA, Verge CF, Rosenberg AR, Meara MW, Walker $\mathrm{JL}$. Isotonic is better than hypotonic saline for intravenous rehidration of children with gastroenteritis: a prospective randomized study. Arch Dis Child 2006;91:226-32.

14. Eisenhut M. Adverse effects of rapid isotonic saline infusion. Arch Dis Child 2006;91:797.

15. Choong K, Kho ME, Menon K, Bohn. Hypotonic versus isotonic saline in hospitalized children: a systematic review. Arch Dis Child 2006;91:826-35. 